\title{
DLC Films Grown On Steel Using An Innovator Active Screen System For PECVD Technique
}

\author{
Patrícia Cristiane Santana da Silva ${ }^{*}$, Marco Antonio Ramirez Ramos ${ }^{a}$, Evaldo José Corat ${ }^{2}$,Vladimir \\ Jesus Trava-Airoldi ${ }^{a}$ \\ anstituto Nacional de Pesquisas Espaciais - INPE, Avenida dos Astronautas, 1758, Jardim da Granja \\ CEP 12227010, São José dos Campos, São Paulo Brazil
}

Received: August 12, 2015; Revised: March 18, 2016; Accepted: June 05, 2016

In this work, an active screen plasma discharge system based technology was incorporated in a PECVD reactor for DLC films growth, making it a new development in DLC films deposition. In this case, the active screen system is used to seek better electrons confinement, which might result in high ions density due to the collisions number increase, leading to a possible increase in ionization. DLC films were grown on steel substrates, using two variations of this system. In order to enhance adhesion between coating and substrate, a silicon interlayer was deposited, using different bias voltages. Morphological and structural characterization was performed by scanning electron microscopy, optical profilometry and Raman scattering spectroscopy. Tribological tests were performed by nanohardness, scratch and wear tests. Results showed that the plasma confinement promoted good films adhesion, which may be related to a high sub-implantation. This might be a consequence of the pressure decrease, as well as, to the ions energy distribution narrowing.

\section{Keywords: Active Screen, DLC, PECVD, Adhesion.}

\section{Introduction}

The great scientific and industrial interest in the use of diamond-like carbon (DLC) films is justified by their remarkable mechanical and tribological properties such as high hardness, excellent wear resistance, chemical inertness and a very low friction coefficient, among others, which give a wide range of applications, as high corrosion resistance and biocompatibility ${ }^{1,2,3}$. This combination of unique properties allows the coating to be applied in several areas, such as wear-resistant coating for metallic, ceramic and optical materials, corrosion protection, liquid and vapor transport barriers, electronic devices, electron field emitting cathode materials, electronic packaging, passivation and thermal heat sinks ${ }^{4}$. However, for an effective application of this coating, it is necessary to ensure a high adhesion between film and substrate.

There is a difficulty in depositing DLC films directly onto metallic substrates, especially on steel, and guarantying the coating's adhesion to the substrate. The film's high hardness combined with the difference in thermal expansion coefficient, compared to the substrate, makes it difficult for DLC film to comply with substrate deformation, which can lead to delamination and total failure of the coating, causing poor adhesion and high residual compressive stress. Furthermore, carbon diffuses into the metals delaying the DLC nucleation. And iron has a catalytic effect that leads to the formation of graphite, which can be detrimental to adhesion ${ }^{5,6,7}$. In order to overcome these limitations, and to extend the range of applications of DLC films, different approaches are possible. A thin interlayer of various materials, such as silicon, can be deposited to enhance adhesion and obtain lower compressive stress ${ }^{8}$.

\footnotetext{
* e-mail: patricia.engpro@gmail.com
}

DLC is a metastable form of amorphous carbon with a significant fraction of $\mathrm{sp}^{3}$ bonds ${ }^{1,9}$. Among the various forms of amorphous mixtures formed by carbon, from PECVD (Plasma Enhanced Chemical Vapor Deposition) it is possible to obtain films of a-C:H type, hydrogenated amorphous carbon, and ta-C:H, hydrogenated tetrahedral amorphous carbon. Using the PECVD method, the structure of the films is composed of $\mathrm{sp}^{2}$ hybridization agglomerates interconnected by $\mathrm{sp}^{3}$ hybridization carbon ${ }^{1,9}$. In this work, DLC films were deposited on high speed steel AISI M2, using the plasma enhanced chemical vapor deposition (PECVD) technique, with a silicon interlayer to increase the films adhesion. However, the conventional technique was modified to promote a plasma densification, by modifying internal arrangement of the deposition system.

The active screen plasma nitriding (ASPN) technique was developed in the late 1990s based on the glow discharge plasma and the principle of post-discharge plasma. The essential difference between conventional DC plasma nitriding and active screen plasma nitriding is that, the cathodic potential is applied on a metal screen, which surrounds the working table, and the samples to be treated are placed in a floating potential. Under this electrical condition, the plasma can only be formed on the surface of metal screen rather than on the sample surface. Consequently, the active screen plasma nitriding could overcome the inherent limitations of conventional DC plasma nitriding techniques. It provides a closer control of the structure and depth of nitriding, control of type and thickness of compound layer, due a more uniform plasma distribution. In addition, it is possible to treat different size parts in the same bath ${ }^{10}$. In the past few years, the ASPN technique has been used to treat low alloy steels, stainless steels, tool steels and other steels, achieving identical nitriding effects as the conventional DC plasma nitriding technology. 
However, the ASPN technique provides the possibilities of treating nonelectrical conducting materials such as steel with an oxidised surface and polymeric materials which are unattainable with a conventional DC plasma system ${ }^{11}$.

Based on the ASPN technique, two different configurations of active screen were developed, promoting electron confinement effect. Tribological tests were performed to analyze the adhesion between film and substrate, the friction coefficient, and wear resistance. Raman spectroscopy technique was used to verify the structural arrangement of carbon atoms and to obtain important parameters. Results showed that among all tested methods, deposition using active screen showed the best results in adherence gain, combined with the application of high-energy ion bombardment in the silicon interface deposition.

\section{Experimental Procedures}

DLC films were deposited over AISI M2 steel substrates $(1.0 \mathrm{~cm} \times 1.0 \mathrm{~cm} \times 0.4 \mathrm{~cm})$ by a modified Plasma Enhanced Chemical Vapor Deposition system. In order to seek a denser and more reactive plasma, based on the electrons confinement, two different configurations of active screen cathodes were tested, which were called active screen partial system, and active screen system. Both of them are a cylindrical cathode, made of a steel mesh sheet (Figure 1), which is connected to the sample holder and it is insulated from the anode.

(a)

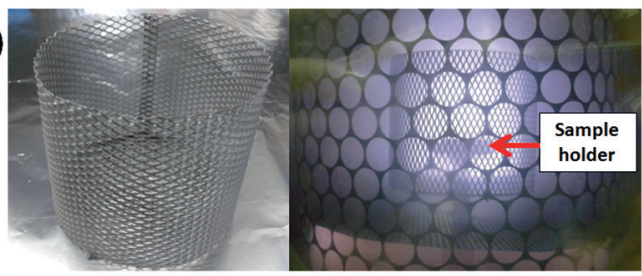

(b)

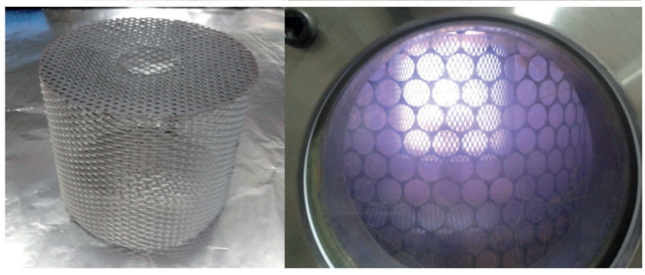

Figure 1: Different cathodes configuration: (a) Active Screen Partial System, (b) Active Screen System

The difference between the two systems is that active screen system is more closed than active screen partial system, since its top section is covered by a plate. A schematic representation of these structures can be visualized in Figure 2.

Samples were polished by using a sequence of different grain sizes to a mirror-like finish surface with approximately $13 \mathrm{~nm}$ of roughness $\left(\mathrm{R}_{\mathrm{a}}\right.$, average amplitude of the surface roughness) (Figure $3 \mathrm{a}$ ), and cleaned ultrasonically in an acetone bath for $10 \mathrm{~min}$. The substrate was mounted on the screen cathodes in the plasma chamber. The cathode was powered by two different pulsed DC power supplies, which cover different voltage ranges, $-100 \mathrm{~V}$ to $1000 \mathrm{~V}$, and -1 to $-10 \mathrm{kV}$. The repetition rate was of $2-20 \mathrm{kHz}$, with squarewave shape pulse, and duty-cycle of $50 \%$. The vacuum base (a)

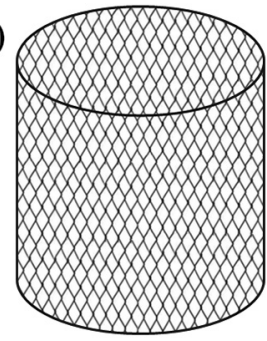

(b)

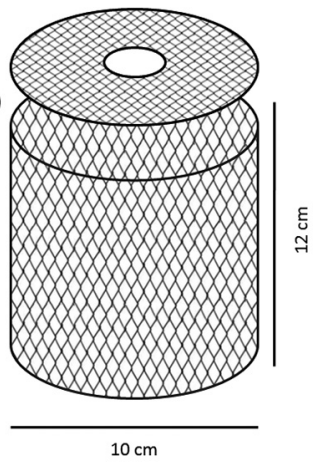

Figure 2: Schematic representation of (a) Active Screen Partial System, (b) Active Screen System.

pressure of the chamber was $0.0013 \mathrm{~Pa}$. The substrates were also cleaned by an argon discharge with $5 \mathrm{sccm}$ gas flow at the lowest working pressure in each system, 5.30 $\mathrm{Pa}$ and 0.66 Pa for the Active Screen Partial System, and the Active Screen System, respectively, and discharge voltage of - $600 \mathrm{~V}$ for $30 \mathrm{~min}$ prior to deposition. In order to enhance adhesion between coating and substrate, a silicon interlayer was deposited using silane as precursor gas. The bombardment energy influence during this deposition step was analyzed, according to the used active screen cathode. The silicon deposition was carried out using a discharge voltage range of -2 to $-8 \mathrm{kV}$, with $3 \mathrm{sccm}$ gas flow, during 5 minutes, and the lowest pressure necessary to maintain the discharge, which was of $6 \mathrm{~Pa}$ and $0.66 \mathrm{~Pa}$ for the Active Screen Partial System, and the Active Screen System, respectively. The aim is to reach the lowest value of pressure as possible, to obtain an ion collisionless regime in order to narrow the ion energy distribution. With a more open system, like the partial one, there is a less effective confinement, which makes it necessary to use a higher pressure. Thus, the active screen total system enables the use of lower pressure.

After this, acetylene gas was introduced, with $10 \mathrm{sccm}$ gas flow, in association with $3 \mathrm{sccm}$ silane gas flow using discharge voltage of - $750 \mathrm{~V}$, during 30 minutes. The silane gas flow was reduced in steps, $0.5 \mathrm{sccm}$ every 5 minutes, until its total reduction. Then, DLC films was deposited using acetylene as precursor, with $7.5 \mathrm{sccm}$ gas flow, 6.66 $\mathrm{Pa}$, discharge of $-750 \mathrm{~V}$, for $60 \mathrm{~min}$.

The carbon atoms arrangement was analyzed by using Raman scattering spectroscopy (Renishaw 2000 System) with $\operatorname{Ar}+$ ion laser $(\lambda=514 \mathrm{~nm})$ in backscattering geometry. Raman shift was calibrated with reference to the diamond peak at 1332 $\mathrm{cm}^{-1}$. The hydrogen content in the film was estimated by using the slope of linear fit of the photoluminescence background in the Raman spectra and the $\mathrm{G}$ band intensity ${ }^{12}$. Tribological tests were performed on CETR UMT-2 tribometer, while mechanical tests were performed on Anton Paar MHT NHT micro and nanoindentation tester. In order to evaluate film adherence on substrate and to determine critical load, micro scratch test was performed, in accord to ASTM C1624 ${ }^{13}$. A diamond stylus Rockwell C with angle of $120^{\circ}$ and $200 \mu \mathrm{m}$ radius was used. The critical load was defined as the value in which the first crack occurs and the friction coefficient increases. For wear test, the tribometer was adjusted for 

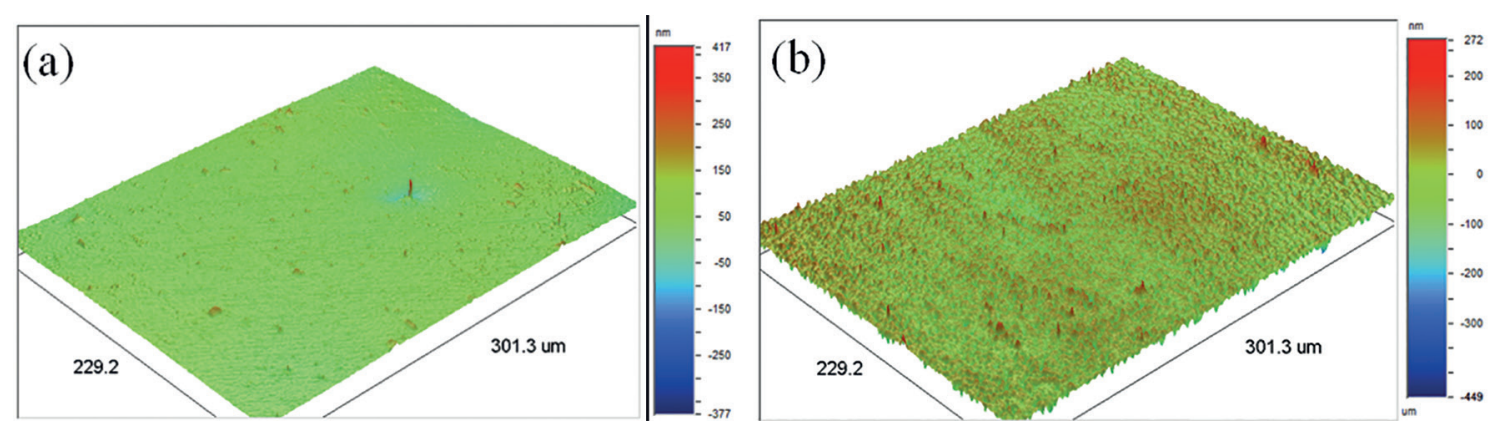

Figure 3: Surface roughness of (a) uncoated sample, (b) DLC film.

ball-on-plate mode, in the reciprocating manner. To validate the DLC film protective effect, four samples of uncoated steel were tested in comparison with eight DLC film coated samples, four prepared by each system. The coefficient of friction was monitored by a strain-gauge sensor, projected to measure normal and lateral force, during 2000 cycles at room temperature and humidity. The linear speed used was $16 \mathrm{~mm} / \mathrm{s}$, with displacement distance of $4 \mathrm{~mm}$, and load of $2 \mathrm{~N}$. Alumina $\left(\mathrm{Al}_{2} \mathrm{O}_{3}\right)$ ball $(4,75 \mathrm{~mm}$ diameter $)$ was used as countersample. The test was performed according to ASTM G133-05 ${ }^{14}$. Optical profilometry was used to evaluate wear test, using in a Veeco Wyko NT 1100 profilometer. Microindentation tests were performed by using a Vickers indenter, with maximum depth of $500 \mathrm{~nm}, 10 \mathrm{mN}$ of contact force, and loading rate of $10000 \mathrm{~nm} / \mathrm{min}$. Five measurements were made in each sample. SEM images were obtained using a JEOL JSM 5310 scanning electron microscope, using secondary electrons for the track images and backscattered electrons for cross sectional images. The samples used for cross sectional images were cutted by diamond cutting disc and polished by using diamond polishing paste with different grain size.

\section{Results and discussion}

Figures $3 \mathrm{a}$ and $3 \mathrm{~b}$ show surface roughness of uncoated and coated samples. Measurements of arithmetic average roughness, made with an optical profilometry, showed average roughness values of $13.2 \pm 1.8 \mathrm{~nm}$ for substrate without DLC film and $33.4 \pm 1.5 \mathrm{~nm}$ for DLC film. The film surface roughness seems to replicate substrate surface roughness. In general, DLC surface roughness has been found to depend on the ion energy, substrate temperature, substrate materials and film composition ${ }^{15}$. Figure 4 exposes the cross sectional SEM image of DLC film and interface. The coating has a thickness of about $11 \mu \mathrm{m}$. It can be observed that about $4.5 \mu \mathrm{m}$ is related to interface thickness, which provides a deposition rate of about $4.3 \mu \mathrm{m} / \mathrm{h}$.

Raman spectroscopy results are exhibited in Table 1, according to cathode used. The obtained parameters are D and $\mathrm{G}$ bands position, width at half maximum (FWHM) of $\mathrm{G}$ band, $\mathrm{D}$ and $\mathrm{G}$ intensities ratio $\left(\mathrm{I}_{\mathrm{D}} / \mathrm{I}_{\mathrm{G}}\right.$, and hydrogenation of the DLC films.

Many authors have observed a strong dependence of $\mathrm{D}$ and $\mathrm{G}$ bands position and width, and the ratio of their intensities $\left(\mathrm{I}_{\mathrm{D}} / \mathrm{I}_{\mathrm{G}}\right.$ ) with the structural mechanical and optical

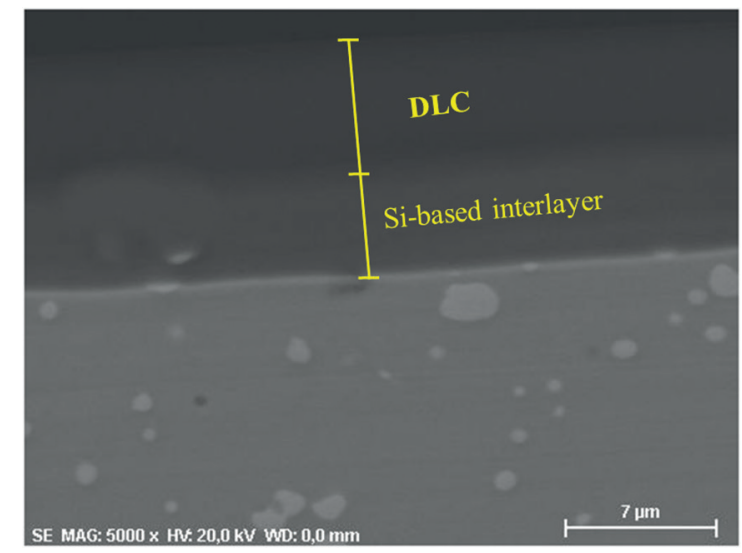

Figure 4: Cross sectional SEM image of DLC film and interface.

properties of the DLC films, and the deposition system ${ }^{16,17}$. $\mathrm{D}$ and $\mathrm{G}$ band positions are, therefore, an indicative of DLC properties ${ }^{1}$. For both DLC films group obtained by the active screen partial system and active screen system, a very small variation is observed in bands position. The $\mathrm{G}$ band position shows little variation with the interface bombardment energy, since there is a conservative behavior in the $\mathrm{sp}^{2}$ and $\mathrm{sp}^{3}$ hybridizations proportion. It was also observed that there was no significant difference in $\mathrm{I}_{\mathrm{D}} / \mathrm{I}_{\mathrm{G}}$ ratio for both systems, which means there were no structural changes with the interface growth variation

The DLC films hydrogenation did not present many variations, when each system is analyzed separately. For coatings grown in the partial system, the hydrogen content varied in a range from 21 to $22 \%$. In the active screen system, the hydrogenation was about $20 \%$. Therefore, in both cases, the films presented diamond-like characteristic. It can be seen that interface growth voltage variations did not affect the structural arrangement of carbon atoms, or quality of the DLC film, since D and G bands position, hydrogenation, $\mathrm{I}_{\mathrm{D}}$ ${ }_{\text {IG }}$ ratio showed no significant variations.

However, when the Raman parameters are compared for DLC film obtained in each system, more significant changes can be observed. FWHM values of $(G)$ and $G$ band position measure the material disorder. A decrease of FWHM (G) can be seen for the samples prepared by the active screen system, in relation to those prepared by the active screen partial system. FWHM (G) is more sensitive to structural disorder of graphitic clusters, while $\mathrm{G}$ band position is more sensitive to topological disorder. The structural disorder 
Table 1: Summarized Raman spectra results of DLC films according to system and bias voltage.

\begin{tabular}{lcccccc}
\hline System & Bias Voltage $(-\mathrm{kV})$ & $\mathrm{D}$ Band $\left(\mathrm{cm}^{-1}\right)$ & $\mathrm{G} \mathrm{Band}\left(\mathrm{cm}^{-1}\right)$ & $\mathrm{FWHM}(\mathrm{G})\left(\mathrm{cm}^{-1}\right)$ & $\mathrm{I}_{\mathrm{D}} / \mathrm{I}_{\mathrm{G}}$ & $\% \mathrm{H}$ \\
\hline \multirow{3}{*}{ Active Screen Partial System } & 2 & 1367.02 & 1548.02 & 159.46 & 0.55 & 22 \\
& 4 & 1360.72 & 1546.39 & 160.47 & 0.52 & 21 \\
& 6 & 1364.59 & 1548.79 & 159.69 & 0.54 & 22 \\
& 8 & 1365.91 & 1545.75 & 163.11 & 0.51 & 21 \\
Active Screen System & 2 & 1386.47 & 1558.52 & 151.43 & 0.70 & 20 \\
& 4 & 1387.95 & 1559.83 & 152.89 & 0.70 & 20 \\
& 6 & 1383.83 & 1559.40 & 153.91 & 0.69 & 20 \\
& 8 & 1386.29 & 1559.23 & 152.47 & 0.68 & 20 \\
\hline
\end{tabular}

increases with the length and bond angle distortions between the atoms, while the topological disorder increases with the size and shape of $\mathrm{sp}^{2}$ agglomerates distribution ${ }^{17}$. This decrease in FWHM is an evidence that the structural disorder of the active screen system prepared films is lower. Similar relationship between the values of FWHM $(\mathrm{G})$ and disorder was found by $\mathrm{Kahn}^{18}$.

When the $\mathrm{G}$ band position and the hydrogen content of DLC films are analyzed, it can be seen that the G band position increases with hydrogen content decrease for DLC films by using active screen system. Tamor and Vasse ${ }^{19}{ }^{\text {observed }}$ a decrease in $G$ band position and the $I_{D} / I_{G}$ ratio according to the increase of $\mathrm{sp}^{3}$ atoms fraction. Noting the increase of $\mathrm{I}_{\mathrm{D}} / \mathrm{I}_{\mathrm{G}}$ ratio in coatings grown by the active screen system compared to partial system, it can be inferred that there is a slight trend to increasing graphitic clusters size in these films.

The $\mathrm{I}_{\mathrm{D}} / \mathrm{I}_{\mathrm{G}}$ ratio increase was observed in studies of the heat treatment effect on carbon films ${ }^{20}$. The authors noted that $\mathrm{D}$ and $\mathrm{G}$ bands positions deviate to higher frequencies, and that their widths decrease as function of temperature. This was attributed to an increase in the number or size of graphite crystals, in association with structural change of random distribution to the bond angles in a structure containing microcrystals with $\mathrm{sp}^{2}$ hybridisation ${ }^{21}$. By using the active screen system, the high reactive ions density in plasma leads to a tendency of increasing deposition temperature. This occurs due to increased trapping of ions in relation to active screen partial system. It can be inferred that this provides an increase in the $\mathrm{I}_{\mathrm{D}} / \mathrm{I}_{\mathrm{G}}$ ratio. In Figure 5 Raman spectra of DLC films obtained in each system are exposed.

Hardness and elastic modulus of DLC films were measured by microindentation. For DLC films obtained by the active screen total system, the obtained average values were $21.4 \pm 2.6 \mathrm{GPa}$, and $176.9 \pm 5.0 \mathrm{GPa}$, respectively. For DLC films obtained by the active screen total system, the obtained average values were $20.8 \pm 1.8 \mathrm{GPa}$, and $163.3 \pm 1.4$ $\mathrm{GPa}$, respectively. There was no difference in films hardness according to bias voltage variation for both systems. The load vs displacement curve is presented in Figure 6. Since the penetration depth was prescribed in $500 \mathrm{~nm}$, it ensures that there was no substrate influence in the measurements. Therefore, DLC films showed high hardness due to their diamond-like feature, which is consistent to hydrogenation results obtained by the Raman spectra.

DLC films adhesion was evaluated according to energy variation in interface deposition, for each system. Critical load values are shown in Table 2. For both samples group,
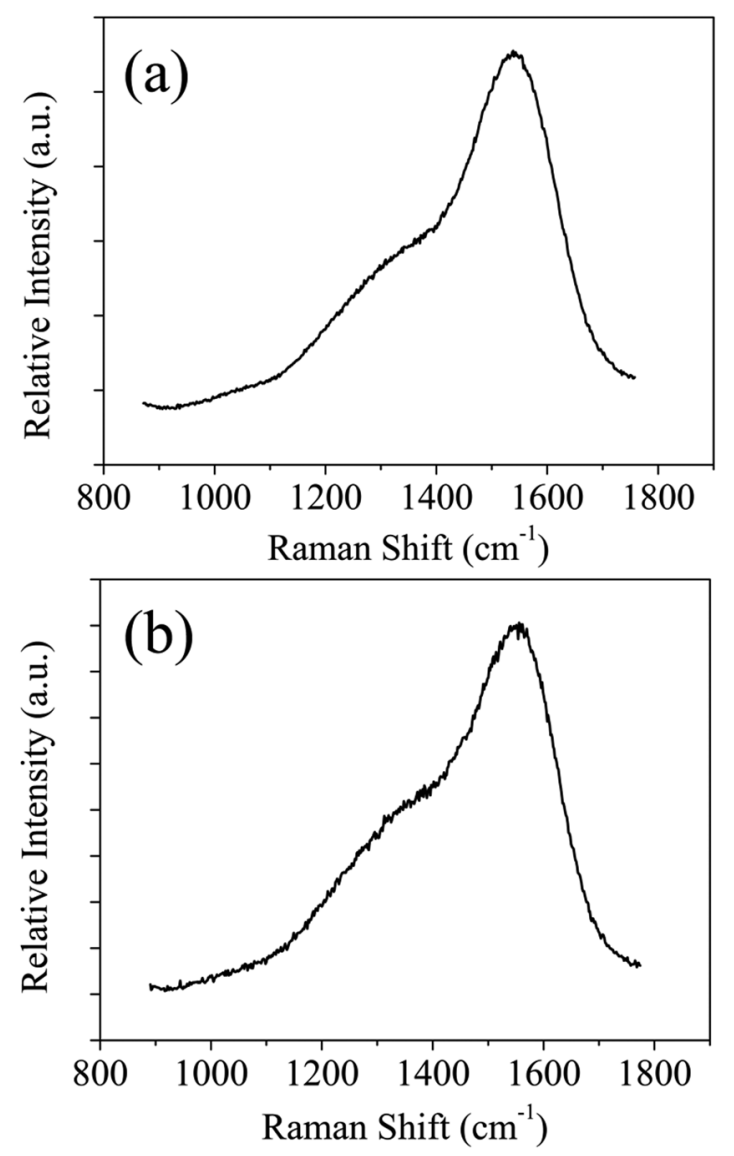

Figure 5: Raman spectra for DLC film obtained with (a) Active Screen Partial System, (b) Active Screen System.

films adhesion increased almost linearly according to the bias voltage increase during silicon interface deposition. Similar results of enhanced adhesion were also obtained by Ward ${ }^{22}$.

When films adhesion is compared for each system, a much higher performance was observed for the samples grown in active screen system, as presented in Table 2. By using this system, even the lowest adhesion value, which occurred for the lower bias voltage $(-2 \mathrm{kV})$, was higher than the highest value displayed for DLC film deposited by using the active screen partial system, with the higher bias voltage $(-8 \mathrm{kV})$. Scratch tracks can be visualized in Figure 7, which exposes an initial film crack (Figure 7a) and a final track point (Figure 7b), where total film failure occurs. It 

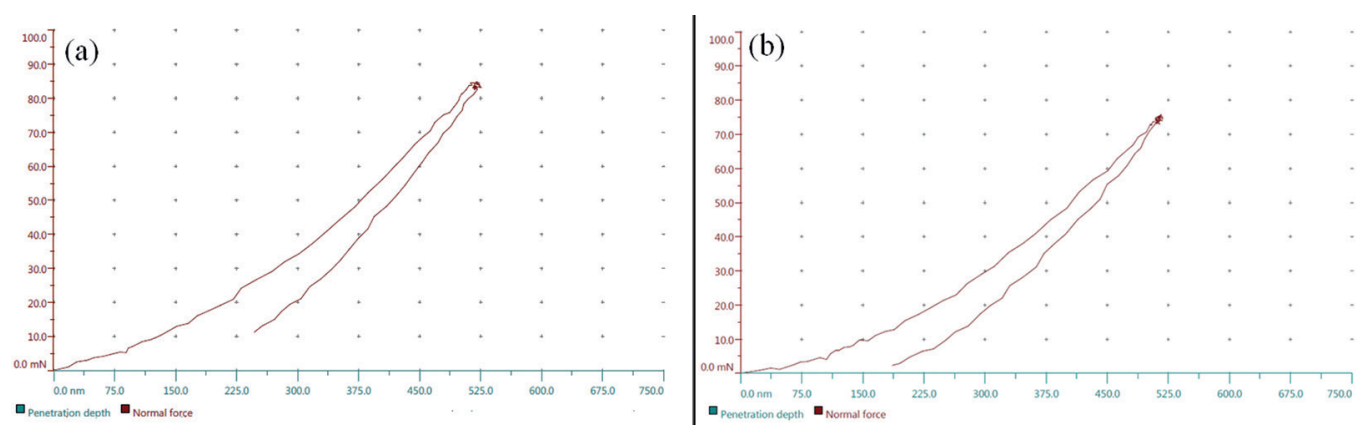

Figure 6: Load vs displacement curve for DLC films obtained by (a) Active screen total system, (b) Active screen partial system.

Table 2: Average critical load for DLC films.

\begin{tabular}{lcc}
\hline System & Bias Voltage $(-\mathrm{kV})$ & Critical Load $(\mathrm{N})$ \\
\hline & 2 & $13.87 \pm 0.33$ \\
Active Screen & 4 & $15.82 \pm 0.58$ \\
Partial System & 6 & $17.13 \pm 0.39$ \\
& 8 & $18.29 \pm 0.36$ \\
& 2 & $28.26 \pm 0.52$ \\
Active Screen & 4 & $29.09 \pm 0.29$ \\
System & 6 & $31.07 \pm 0.37$ \\
& 8 & $34.83 \pm 0.43$ \\
\hline
\end{tabular}

is possible to observe that tensile crack was followed by chipping and coating spallation, as expected for hard coatings over hard substrates.

Increased adhesion is explained by the use of active screen system. In this system, which is more closed than the active screen partial system, and the conventional cathode, a much lower pressure can be used. At low pressures, an opposite behavior is observed in the deposition rate for active screen systems in relation to conventional PECVD technique. This behavior is more observed in active screen system due to the higher interaction between electrons and molecules. In the low pressure limit, the species distribution rate in plasma is mainly on account of processes induced by electrons ${ }^{23}$. As the concentration of reactive species is decreased, electrons cross section increases with electron energy. Thus, ionization is caused by processes in which free electrons that reach sufficiently high kinetic energy collide with gas molecules promoting molecules ionization. The lower the pressure, the greater is the molecules mean free path and flow regime tends to molecular, due to the fact that there are fewer molecule-molecule collisions. In conventional system, at low pressure conditions, the electrons mean free path also becomes longer, so that the probability of electron-molecule collision decreases, reducing percentage of molecules dissociation and ionization. The result is a reduction in deposition rate and increased plasma instability.

The use of active screen systems provided a similar hollow cathode discharge. This effect is obtained when two parallel plates are cathodically polarized, so that an electron present between them is repeatedly repelled before leaving the inside ${ }^{24}$. Through the use of the active screen system, a better electrons confinement effect was obtained in comparison to the active screen partial system. The system closed form is an electrons confinement region when subjected to a cathodic potential. Thus, high ions density is achieved in this region, since each electron present in it has a greater collisions number with molecules than that outside this region. In this case, the adhesion is influenced by the ionic sub-implantation, since a fraction of incident ions penetrates the surface and densify the film, while others stay on the surface and contributes to the films thickness. Therefore, a better ionic sub-implantation can provide better adhesion and high hardness.

Figure 8 presents the profiles of coated and uncoated samples after the wear test, while friction coefficient graph for each case is exhibited in Figure 9. DLC coating promoted
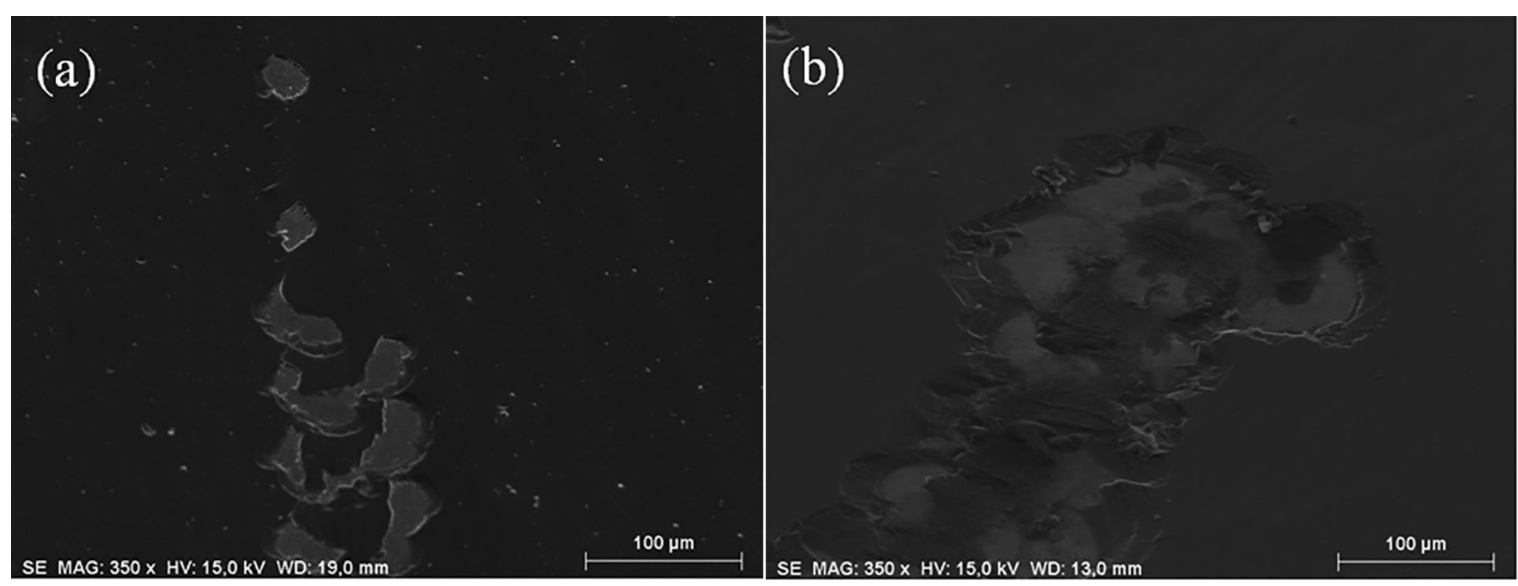

Figure 7: Scratch test tracks (a) Delamination region wedging (b) Final track point. 


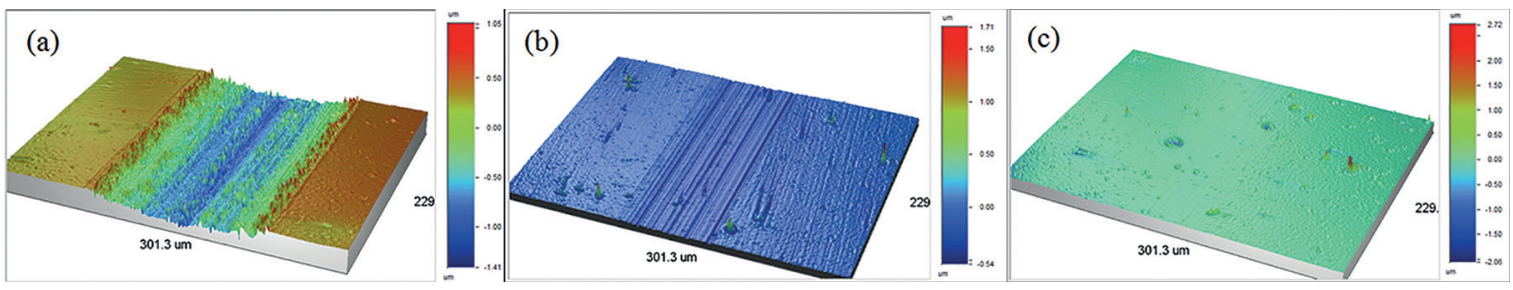

Figure 8: Wear track profiles of (a) uncoated, (b, c) DLC-coated steel.
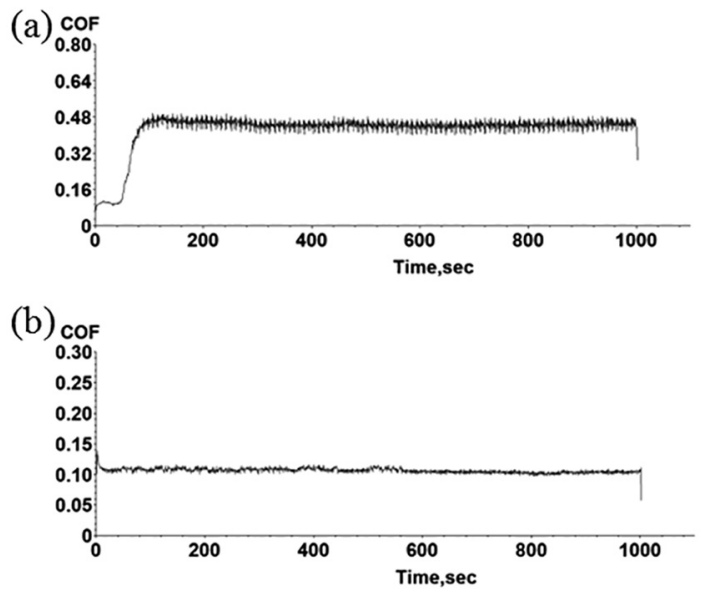

Figure 9: Friction coefficient graph of (a) uncoated sample (b) DLC film.

a protective effect, as expected, which can be observed from the track profile. There were no significant differences in the friction coefficient for films grown by the two different systems. The friction coefficient value for samples grown by both systems were about 0.1 , while the value for uncoated steel was about 0.48 . The wear rate was calculated by using ASTM G133 equations, from the area measured by optical profilometry. For uncoated samples (Figure 8a), the wear rate was around $10^{-7} \mathrm{~mm}^{3} / \mathrm{N}$.m, while for DLC coated samples, they were around $10^{-9}$ and $10^{-10} \mathrm{~mm}^{3} / \mathrm{N} . \mathrm{m}$, for films obtained by the active screen partial system (Figure $8 \mathrm{~b}$ ) and active screen system (Figure 8c), respectively. The results values indicates the order of magnitude of the wear rate for the tested samples.

\section{Conclusions}

In this work, it was possible to obtain a denser plasma by using active screens, based in electron confinement effect in the cathode region, which probably results in a high degree of species activation. Two systems configurations were evaluated, total and partial active screens. According to results, both systems provided DLC films with good structural quality and homogeneity, high hardness and good wear resistance. However, scratch tests showed differences between the films obtained by the two systems. The active screen total system provided films with superior adhesion to the substrate, besides a smaller wear rate. This may be related to the pressure decrease, and the narrowing of ions distribution energy.
The electrons confinement may have provided high ions density, due to the larger number of collisions between electrons and molecules, which increases ionization. Ion bombardment energy during the interface growth was also studied, and presented a behavior directly proportional to films adhesion. With the bias voltage increase during silicon interface deposition, it was possible to obtain DLC films better adhered to the substrate.

\section{Acknowledgments}

The authors would like to thank FAPESP and CNPq for financial support.

\section{References}

1. Robertson J. Diamond-like amorphous carbon. Materials Science and Engineering: R: Reports. 2002;37(4-6):129-281.

2. Vetter J. 60 years of DLC coatings: Historical highlights and technical review of cathodic arc processes to synthesize various DLC types, and their evolution for industrial applications. Surface and Coatings Technology. 2014;257:213-240.

3. Zhang W, Tanaka A, Xu BS, Koga Y. Study on the diamond-like carbon multilayer films for tribological application. Diamond and Related Materials. 2005;14(8):1361-1367.

4. Grill A. Diamond-like carbon: state of the art. Diamond and Related Materials. 1999;8(2-5):428-434.

5. Dalibon EL, Trava-Airoldi V, Pereira LA, Cabo A, Brühl SP. Wear resistance of nitrided and DLC coated PH stainless steel. Surface and Coatings Technology. 2014; 255:22-27.

6. Neto VF, Oliveira MSA, Ali N, Grácio J. Time-modulated chemical vapour deposition diamonf on mould making 2738 steel. Vacuum. 2008;82(12):1346-1349.

7. Neto VF, Vaz R, Oliveira MSA, Grácio J. CVD diamond-coated steel inserts for thermoplastic mould tools - Characterization and preliminary performance evaluation. Journal of Materials Processing Technology. 2009;209(2):1085-1091.

8. Trava-Airoldi VJ, Santos LV, Bonetti LF, Capote G, Radi PA, Corat E. Tribological and mechanical properties of DLC film obtained on metal surface by enhanced and low-cost pulsedDC discharge. International Journal of Surface Science and Engineering. 2007;1(4):417-428.

9. GRILL A. Electrical and optical properties of diamond-like carbon. Thin Solid Films 1999;(355-356):189-193.

10. Lin K, Li X, Sun Y, Luo X, Dong H. Active screen plasma nitriding of 316 stainless steel for the application of bipolar plates in proton exchange membrane fuel cells. International Journal of Hydrogen Energy. 2014;39(36):21470-21479.

11. Li CX. Active screen plasma nitriding - an overview. Surface Engineering. 2010; 26(1-2):135-141. 
12. Casiraghi C, Ferrari AC, Robertson J. Raman spectroscopy of hydrogenated amorphous carbons. Physical Review $B$. 2005;72(8):085401.

13. American Society for Testing and Materials (ASTM). C1624-05: Standard Test Method for Adhesion Strength and Mechanical Failure Modes of Ceramic Coatings by Quantitative Single Point Scratch Testing. West Conshohocken: ASTM International; 2010. 29p.

14. American Society for Testing and Materials (ASTM). G133-05: Standard test method for linearly reciprocating ball-on-flat sliding wear. West Conshohocken: ASTM International. 9p.

15. Peng XL, Barber ZH, Clyne TW. Surface roughness of diamondlike carbon films prepared using various techniques. Surface and Coatings Technology. 2001;138(1):23-32.

16. Ferrari AC, Robertson J. Raman spectroscopy of amorphous, nanostructured, diamond-like carbon, and nanodiamond. Philosophical Transactions of the Royal Society of London. A. 2004;362(1824):2477-2512.

17. Ferrari AC, Robertson J. Interpretation of Raman spectra of disordered and amorphous carbon. Physical Review B. 2000;61(20):14095-14107.

18. Kahn M, Paskvale S, Čekada M, Schöberl T, Waldhauser W, Mitterer C, et al. The relationship between structure and mechanical properties of hydrogenated amorphous carbon films. Diamond and Related Materials. 2010;19(10):1245-1248
19. Tamor MA, Vassell WC. Raman "fingerprinting" of amorphouscarbon films. Journal of Applied Physics. 1994;76(6):3823-3830.

20. Kamiya M, Tanoue H, Takikawa H, Taki M, Hasegawa Y, Kumagai M. Preparation of various DLC films by T-shaped filtered arc deposition and the effect of heat treatment on film properties. Vacuum. 2008;83(3):510-514.

21. Adliené D, Laurikaitiené J, Kopustinskas V, Meškinis Š, Šablinskas V. Radiation induced changes in amorphous hydrogenated DLC films. Materials Science and Engineering: B. 2008;152(1-3):91-95.

22. Ward L, Junge F, Lampka A, Dobbertin M, Mewes C, Wienecke $\mathrm{M}$. The effect of bias voltage and gas pressure on the structure, adhesion and wear behavior of Diamond Like Carbon (DLC) coatings with Si interlayers. Coatings. 2014;4(2):214-230.

23. Michelmore A, Whittle JD, Short RD. The importance of ions low pressure PECVD plasmas. Frontiers in Physics. 2015;3(3):5p.

24. Pang X, Peng H, Yang H, Gao K, Wu X, Volinsky AA. Fast deposition of diamond-like carbon films by radio frequency hollow cathode method. Thin Solid Films. 2013;534:226-230. 